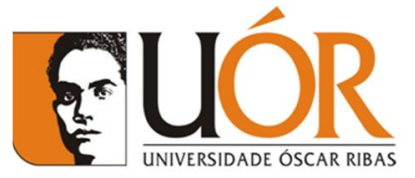

\title{
ANÁLISE DA CORRELAÇÃO ENTRE A SATISFAÇÃO NO TRABALHO E O COMPROMETIMENTO ORGANIZACIONAL: ESTUDO COM OS ENFERMEIROS DA PEDIATRIA DO HOSPITAL GERAL DE LUANDA
}

\author{
Analysis of the correlation between job satisfaction and organizational \\ commitment: Study with the pediatric nurses of the General Hospital of Luanda / \\ Análisis de la correlación entre la satisfacción en el trabajo y el compromiso \\ organizacional: Estudio con los enfermeros de pediatría del Hospital General de \\ Luanda
}

Mirian Nareti Luís Neves ${ }^{1}$

\section{RESUMO}

Levando-se em conta que o processo de desenvolvimento da satisfação e o comprometimento no indivíduo é um assunto que tem gerado interesse de distintos pesquisadores, para o entendimento do mecanismo das relações entre as organizações e seus funcionários, qualquer factor que contribua para 0 desenvolvimento destes constructos age por meio de seu impacto sobre uma ou mais predisposições psicológicas, as quais levam um indivíduo a comportar-se de determinada maneira em relação a algo ou alguém. A satisfação e o comprometimento dos funcionários são constructos relevantes que podem conduzir às vantagens competitivas e ao sucesso da organização. Neste estudo tem-se como objectivo, analisar a correlação entre satisfação no trabalho e o comprometimento dos Enfermeiros da Pediatria do Hospital Geral de LuandaAngola (HGL). Para levar a cabo se revisou as teorias da hierarquia das necessidades de Maslow e a teoria dos factores higiénicos e motivacionais de Herzberg. Utilizaram -se igualmente os aportes de Chiavenato (2010); (Ferreira, Neves e Caetano 2011); Myers (2006); (Rojot, Roussel e Vanderberghe 2009); Spector (2006) e Teixeira (2005). Para este estudo foi realizado uma pesquisa do tipo quantitativa, com ênfase no método exploratório-descritivo. Os dados foram recolhidos por meio de dois questionários, os quais foram submetidos a análises de percentagem e médias, bem como, a correlações. Constatou-se baixo grau de satisfação com o salário $(2,40)$, grau de satisfação médio na importância do trabalho $(3,95)$ e um alto grau de satisfação na relação com os colegas $(4,23)$. Há predominância do comprometimento normativo nos enfermeiros da Pediatria do HGL, também foi identificada uma correlação fraca $(0,27)$ entre a satisfação no trabalho e o comprometimento normativo.

Palavras-chave: Satisfação no Trabalho, Comprometimento Organizacional, Correlação, Hospital Geral de Luanda.

Recebido: Setembro 2017

Aceitado: Novembro 2017

\footnotetext{
${ }^{1}$ Universidade Oscar Ribas. Luanda, Angola. Correio eletrônico: miriannareth.scout@gmail.com
} 


\title{
RESUMEN
}

Tomando en cuenta que el proceso de desarrollo de la satisfacicon y compromiso del individuo es un asunto que genera interés en los investigadores, para la comprensión de los mecanismos de las relaciones entre las organizaciones y sus funcionarios, ya que, cualquier factor que contribuya para el desarrollo de estos constructos a través de su impacto sobre una o mas predisposiciones psicológicas, llevaran al individuo a comportarse de determinada manera en relación a algo o alguien. La satisfacción y el compromiso de los funcionarios son constructos relevantes que pueden conducir al logro de ventajas competitivas y el éxito de la organización. Este estudio tiene como objetivo analizar la correlacion entre la satisfación del trabajo y el compromiso de los enfermeros de pediatría en el Hospital General de Luanda. Para llevarlo a cabo, se revisaron las teorías de jerarquía de las necesidades de Maslow y la teoría de los factores higienicos y motivacionales de Herzberg, usando los aportes de Chiavenato (2010); Ferreira, Neves y Caetano (2011);Myers (2006); Rojot, Roussel y Vanderberghe (2009); Spector(2006) yTeixeira (2005). Para este estudio fue realizada una investigación de tipo cuantitativa con método exploratorio-descriptivo. Los datos fueron recogidos por medio de 2 cuestionarios, que se sometieron al análisis de porcentajes y medias, asi como, las correlaciones. Encontrandose un bajo grado de satisfacción con respecto al salario $(2,40)$, grado de satisfacción medio en la importancia del trabajo $(3,95)$ y un alto grado de satisfacción en relación con los colegas $(4,23)$. Predomina el compromiso normativo de los enfermeros de pediatría del HGL, también fue identificada una correlacion debil $(0,27)$ entre la satisfacción del trabajo y el compromiso normativo.

Palabras Clave: satisfacción en el trabajo, compromiso organizacional, correlación, Hospital General de Luanda.

\begin{abstract}
Being taken into account that the process of development of the satisfaction and the compromising in the individual are a subject that has been generating interest in the researchers, for the understanding of the mechanism of the relationships between the organizations and their employees, any factor that contributes to the development of these constructos acts through his/her impact on an or more psychological predispositions, which take an individual to hold certain way in relation to something or somebody. The satisfaction and the employees' compromising are relevant constructs that can lead to the competitive advantages and the success of the organization. In this study it is had as objective to analyze the correlation among satisfaction in the work and the compromising of the Nurses of the Pediatrics of the General Hospital of Luanda. To take to cable it was revised the theories of the hierarchy of the needs of Maslow and the theory of the factors hygienic and motivation is of Herzberg, with a lot of frequency it was used the contributions of Chiavenato (2010); Ferreira, Neves and Caetano (2011); Myers (2006); Rojot, Roussel and Vanderberghe (2009); Spector (2006) and Teixeira (2005). Para this study a research of the quantitative type was accomplished, of
\end{abstract}


Análise da correlação entre a satisfação no trabalho e o comprometimento organizacional: estudocom os enfermeiros da pediatria do hospital geral de luanda

method exploratory-descriptive. The data were collected through two questionnaires, which it was submitted there are percentage analyses and averages, as well as, to correlations. Low satisfaction degree was verified with the wage $(2,40)$, medium satisfaction degree in the importance of the work $(3,95)$ and a high satisfaction degree in the relationship with the friends $(4,23)$. There is predominance of the normative compromising in the nurses of the Pediatrics of HGL, it was also identified a weak correlation $(0,27)$ among the satisfaction in the work and the normative compromising.

Keywords: Satisfaction in the Work, Organizational Compromising, Correlation, General Hospital of Luanda.

\section{INTRODUÇÃO}

O lugar que os profissionais ocupam como diferencial competitivo nas organizações evidencia a necessidade de mantê-los satisfeitos e dar condições de desenvolvimento. Não basta ter profissionais competentes em uma empresa, deve-se, antes, oferecer condições para que desenvolvam o seu potencial a fim de que se comprometam com a organização e produzam os resultados almejados.

A satisfação e comprometimento dos enfermeiros é muito importante porque, melhora a manutenção e recuperação da saúde nas famílias, reduz o índice de mortalidade infantil na sociedade e melhora a qualidade da prestação de serviço nos hospitais (Rodrigues, 2006).

Em 1979, na 61a conferência da OIT foram discutidas condições insatisfatórias do trabalho de enfermagem relacionadas à factores como: extensas jornadas de trabalho, ausência de períodos de descanso, plantões aos domingos e feriados sem justa compensação, períodos de trabalho fatigantes e o facto de a equipa de enfermagem não ser ouvida quanto ao planeamento e a tomada de decisões da prática profissional, do ensino e das condições de trabalho (Cecagno, 2005).

A satisfação no trabalho é um constructo geral que engloba diversas facetas. Assim, não se fala unicamente de satisfação global, mas também de satisfação face a certos aspectos específicos do trabalho, sendo os mais correntes a remuneração, as promoções, os colegas, a supervisão e o trabalho em si (Smith, Kendall e Hulin, 1999, citados por Rojot, Roussel e Vandenberghe, 2009). 
Portanto, a satisfação no trabalho (ST) "é uma variável de atitude que mostra como as pessoas sentem-se em relação ao trabalho que têm, de forma geral em seus vários aspectos" (Spector, 2006, p.321). A satisfação no trabalho pode ser abordada de formas diversas, desde o conteúdo do trabalho e os aspectos psicossociais, nos quais as características das actividades actuam no surgimento da motivação, do indivíduo até sua expansão para outros contextos (Sant'Anna, Moraes e Kilimnik, 2005).

O acto de trabalhar dentro da organização, mediante pressões e conflitos diversos torna-se bastante complexo. Spector (2002) apresenta duas abordagens distintas na concepção e análise do trabalho de um indivíduo: abordagem orientada ao trabalho e abordagem orientada à pessoa.

O comprometimento do colaborador para com a sua empresa é fundamental para o sucesso da mesma, entretanto, o retorno deve ser recíproco. Este acto de empenho e lealdade entre as partes fortalece a estrutura da organização.

Conforme o estudo de Mowday, Steerse Porter (1979, citados por Spector, 2002) o comprometimento organizacional é formado por três componentes: aceitação dos objectivos da empresa; disposição para trabalhar com dedicação pela organização e desejo de permanecer na organização.

Mais recentemente, uma nova concepção sobre o assunto foi desenvolvida e o comprometimento foi dividido em três tipos: afectivo, contínuo e normativo (Meyer, Allene Smith, 1993, citados por Spector, 2006).

- O comprometimento organizacional afectivo refere-se ao vínculo emocional e à identificação do funcionário com a organização.

- O comprometimento organizacional contínuo refere-se ao comprometimento baseado nas perdas que o funcionário associa à sua saída da organização.

- O comprometimento organizacional normativo refere-se ao sentimento de obrigação do funcionário de permanecer na organização.

Esta pesquisa tem como objectivo geral analisar a correlação entre a satisfação no trabalho e o comprometimento organizacional dos enfermeiros da 
Análise da correlação entre a satisfação no trabalho e o comprometimento organizacional: estudocom os enfermeiros da pediatria do hospital geral de luanda

Pediatria do Hospital Geral de Luanda, a mesma foi definida como quantitativa de modelo exploratório-descritivo, na qual analisaram-se os factores associados à satisfação no trabalho e o comprometimento organizacional em um grupo específico de profissionais. Seu cunho exploratório-descritivo deve-se a finalidade de proporcionar mais informações sobre os constructos bem como maior intimidade com o problema, com vista a torná-lo mais explícito.

\section{FUNDAMENTAÇÃO TEÓRICA}

São inúmeras as definições existentes do de conceito de comprometimento organizacional e de satisfação no trabalho, sendo, contudo, possível categorizálas de acordo com as seguintes perspectivas-distintas.

Para Muchinsky (2004, p. 301) a satisfação no trabalho "é o grau de prazer que um funcionário tem com o seu trabalho". O mesmo autor define o comprometimento organizacional como sendo "o grau de fidelidade de um funcionário com o seu empregador" (p. 306).

Para Newstrom (2008, p. 202) a satisfação no trabalho "é um conjunto de sentimentos e emoções favoráveis ou desfavoráveis por meio dos quais os funcionários vêm seu trabalho". Já o comprometimento "é o grau que um trabalhador se identifica com a organização e demonstra sua vontade de permanecer participando activamentedela" (p. 205).

Para Spector (2006, p. 321) a satisfação no trabalho "é uma variável de atitude que mostra como as pessoas sentem-se em relação ao trabalho que têm de forma geral em seus vários aspectos". O autor define o comprometimento organizacional como "o vínculo que o funcionário tem com a organização" (p. 349).

Já Meyer e Herscovitch (2001, p. 301) definem o comprometimento como uma "força que liga um indivíduo a uma linha de conduta permanente para um ou vários alvos".

\section{Satisfação no trabalho}

A satisfação no trabalho é um constructo geral que engloba diversas facetas. Assim, não se fala unicamente de satisfação global, mas também de 
satisfação face a certos aspectos específicos do trabalho, sendo os mais correntes a remuneração, as promoções, os colegas, a supervisão e o trabalho em si (Smith, Kendall e Hulin, 1999, citados por Rojot, Roussel e Vandenberghe, 2009).

$O$ acto de trabalhar dentro da organização, mediante pressões e conflitos diversos torna-se bastante complexo. Spector (2002) apresenta duas abordagens distintas na concepção e análise do trabalho de um indivíduo: abordagem orientada ao trabalho e abordagem orientada à pessoa.

Para Spector (2002) a abordagem orientada ao trabalho está intrinsecamente ligada à natureza das tarefas, actividades e às suas características dentro da organização. Sua incumbência é a de revelar as actividades da pessoa dentro da empresa, ou seja, fornecer uma imagem das funções desempenhadas. As tarefas segundo o autor podem ser subdivididas em funções menores.

No entanto, à abordagem orientada à pessoa destaca os atributos, as característica e as habilidades necessárias ao sucesso no desempenho de um determinado trabalho, tais como: conhecimento, aptidões e outras características pessoais. Algumas enfocam basicamente o desempenho no trabalho, porém, outras estão relacionadas também com a adequação e a satisfação no trabalho.

Segundo Spector (2006) diz que a satisfação no trabalho é pessoal e está relacionada directamente ao sentimento justo em relação a diversas características ambientais, salariais e naturais. Por ser algo tão importante ao bom desempenho pessoal e consequentemente, da empresa, a satisfação do indivíduo é alvo de grandes estudos na área da Psicologia Organizacional.

O referido autor diz que, a satisfação no trabalho tem relação com importantes realizações da empresa e do funcionário quanto à saúde, longevidade e comprometimento com a organização. Já a insatisfação no trabalho é um aspecto que inviabiliza o atendimento das necessidades e expectativas que os trabalhadores têm em relação ao seu desempenho pessoal e profissional (Alcobia, 2001, citado por Ferreira, Neves e Caetano, 2011).

A falta de satisfação ou a insatisfação no trabalho pode causar doenças, afectando a saúde e o bem-estar do trabalhador. Problemas para dormir, dores 
Análise da correlação entre a satisfação no trabalho e o comprometimento organizacional: estudocom os enfermeiros da pediatria do hospital geral de luanda estomacais, ansiedade e depressão foram relacionadas àsatisfação no trabalho (Thomas e Ganster, 1995 citados por Spector, 2006).O facto da insatisfação no trabalho influenciar a saúde e o bem-estar do trabalhador afectatambém a qualidade de vida do mesmo.

A influência mútua, tendo em vista que as situações vividas fora do trabalho podem interferir na ST ou vice-versa (Weaver, 1978, citado por Spector, 2006), é a única hipótese confirmada por estudos.Um factor estreitamente ligado à ST é a motivação do sujeito para a realização de seu trabalho. O movimento humanista propunha, por exemplo, que a forma de aumentar a motivação para o trabalho era oferecer condições que promovessem o aumento da satisfação (Myers, 2006).

Contudo, no subponto a seguir abordaremos as teorias motivacionais que contribuem para a compreensão da satisfação no trabalho.

\section{Teoria da hierarquia das necessidades de Maslow}

Maslow (1970, citado por Myers, 2006, p. 332) apresentou uma teoria da motivação pressupondo que as necessidades humanas estarão hierarquizadas e dispostas em níveis, de acordo com o seu grau de importância e centra as necessidades como explicação fundamental das motivações na sua teoria humanista.

O centro desta teoria é a existência de uma hierarquia no que concernem as necessidades humanas, constituída pelas necessidades biológicas, psicológicas e socias. Maslow (1970, citado por Myers, 2006) sustenta a tese de que somente à medida que as necessidades inferiores da hierarquia são satisfeitas, é que surgirão as necessidades superiores.

A mesma explica que, as necessidades humanas estão arranjadas em uma pirâmide de importância no comportamento humano. Na base da pirâmide estão às necessidades mais baixas e recorrentes - as chamadas necessidades primárias, enquanto no topo estão as mais sofisticadas - as necessidades secundárias, são elas:

- Necessidades Fisiológicas (englobando a necessidade de alimento, água, sexo e abrigo). Quando alguma destas necessidades não está satisfeita, 
todo o comportamento do indivíduo é dirigido para a sua satisfação. Há satisfação quando a remuneração é adequada para satisfazer as necessidades básicas e insatisfação quando há confronto ao local de trabalho e a remuneração é inadequada.

- Necessidades de Segurança (implicam a auto-preservação através do evitamento da ameaça, do perigo e da privação). O funcionário esta satisfeito quando o tipo e o ambiente de trabalho são bem estruturados; políticas da empresa estáveis e previsíveis. Háinsatisfação quando o tipo de trabalho e o seu ambiente é mal estruturada; políticas da empresaimprevisíveis.

- Necessidades Sociais (inclui o desejo de associação, pertença, amizade e de aceitação). A não satisfação destas necessidades conduz á falta de adaptação social e a solidão, cria debilidade no relacionamento interpessoal o que afecta a produtividade. Há satisfação quando há elevada interacção e relacionamento com colegas, chefia e colaboradores. Já a insatisfação ocorre quando há baixa interacção e relacionamento com colegas, chefia e colaboradores.

- Necessidade de estima (englobam a autoconfiança, o reconhecimento, a apreciação, o estatuto e a atenção). Há satisfação dessas necessidades, solidificam sentimentos de autoconfiança, valor, força, prestígio, poder, capacidade. A não realização pode causar sentimentos de inferioridade, fraqueza, dependência e desamparo, os quais podem levar ao desânimo.

- Necessidade de auto-realização (implica competência, concretização do potencial individual e o crescimento).

Segundo Maslow (1970, citado por Teixeira, 2005) uma pessoa nunca está completamente satisfeita quanto às necessidades de qualquer nível. Mas uma determinada necessidade só sobressai como prepotente, isto é, com poder excepcional para influenciar o comportamento, quando as de nível inferior da hierarquia se encontram satisfeitas em elevado grau. 
Análise da correlação entre a satisfação no trabalho e o comprometimento organizacional: estudocom os enfermeiros da pediatria do hospital geral de luanda

\section{Teoria dos factores motivacionais e higiénicos de Herzberg}

Para melhor explicar o comportamento dos indivíduos em situação de trabalho, Herzberg (1959, citado por Teixeira, 2005) considerou que existem dois factores a ter em conta na satisfação do desempenho da função: factores higiénicos ou insatisfatórios e factores motivacionais ou satisfatórios.

Os factores higiénicos são factores extrínsecos, que se localizam no ambiente que rodeia os indivíduos: salário; benefícios sociais; tipo de chefia; condições físicas e ambientais de trabalho; políticas da empresa; clima que reina entre as pessoas no seio da empresa e a relação com os colegas.

Já os factores motivacionais são factores intrínsecos, porque estão sob o controlo do indivíduo. Estes envolvem: sentimentos de crescimento pessoal e reconhecimento profissional.

Em certa medida, osfactores higiénicos podem ser equiparados às necessidades fisiológicas, de segurança e sociais de Maslow e os factores motivacionais, às necessidades de estima e de auto-realização.

\section{Comprometimento organizacional}

Os problemas relacionados ao comprometimento giram basicamente em torno de três variáveis: a idade, o nível ocupacional e o tamanho da organização (Rojot, Roussel e Vandenberghe, 2009). A idade interfere no seguinte sentido, o indivíduo a envelhecer tende a diminuir seu grau de expectativa e motivação, passa a ser mais realista quanto ao trabalho.

Já os níveis ocupacionais, ligados a remunerações, designam o grau de satisfação dos empregados quanto aos salários e quanto aos trabalhos a serem realizados, já que algumas atitudes que requerem maiores habilidades tendem a proporcionar maior satisfação.

Para Rojot, Roussele Vandenberghe (2009) na ligação entre o tamanho da empresa e satisfação destaca-se que quanto maior for a entidade menor serão as proximidades e o elo de ligação tende a diminuir.

Conforme o estudo de Mowday, SteersePorter (1979, citados por Spector, 2002) o comprometimento organizacional é formado por três componentes: 
aceitação dos objectivos da empresa; disposição para trabalhar com dedicação pela organização e desejo de permanecer na organização.

Concebendo o comprometimento organizacional como uma "ligação psicológica que une o indivíduo e a organização", O’Reilly eChatman (1986, citados por Rojot, Roussel e Vandenberghe, 2009, p.328) procuram distinguir as diferentes bases emque essa ligação pode assentar, foram assim propostas três bases de comprometimento: que mencionaremos a seguir:

- Identificação: tem a ver com o processo pelo qual o indivíduo integra certos atributos.

- Características da organização: comprometimento baseado na identificação traduz, por conseguinte, um desejo de aflição com esta. A noção de internalização reflecte uma congruência dos valores do indivíduo com os da organização.

- Aquecimento: ocorre quando um indivíduo adopta certos comportamentos e atitudes, a fim de obter um benefício particular; trata-se de uma implicação instrumental.

Mais recentemente, uma nova concepção sobre o assunto foi desenvolvida e o comprometimento foi dividido em três tipos: afectivo, contínuo e normativo (Meyer, Allene Smith, 1993, citados por Sector, 2006).

Para os autores o comprometimento afectivo (CA) ocorre quando o funcionário deseja permanecer na empresa por razões emocionais. Surge das condições de trabalho e das expectativas atingidas: a actividade forneceu as recompensas que o indivíduo esperava.

Já o comprometimento contínuo (CC) está relacionado com a necessidade de o indivíduo permanecer na empresa devido aos salários e benefícios não encontrados em outro emprego. Resulta dos benefícios obtidos pelo trabalho e a falta de alternativas de tarefas disponíveis.

O comprometimento normativo $(\mathrm{CN})$ está relacionado aos valores do funcionário, quando ele acredita ser este acto a forma correcta de conduta. Vem de valores pessoais e das obrigações que a pessoa julga ter para com o seu emprego. Estas obrigações podem ser resultantes de favores obtidos da 
Análise da correlação entre a satisfação no trabalho e o comprometimento organizacional: estudocom os enfermeiros da pediatria do hospital geral de luanda organização ao longo do tempo, como gastoscom a educação, entre outros benefícios.

Segundo Meyer, Allene Smith (1993, citados por Sector, 2006) há levantamentos que mostram que enquanto os empregadores tentam aumentar os vínculos, os empregados estão procurando reduzir os níveis de compromisso e dependência.

Bowdich e Bouno (2000, p. 39) no prefácio de um estudo sobre a motivação organizacional, destacavam o comprometimento, como a forma com que as pessoas realizavam suas actividades dentro da organização, é um dos principais problemas no estudo do comprometimento empresarial.

Desta forma Siqueirae Gomide (2004) sobre os mesmos tipos de comprometimento explicam que o comprometimento afectivo corresponde ao desejo, o contínuo à necessidade e o normativo é a obrigação moral.

$\mathrm{Na}$ maioria das organizações, a qualidade que os líderes mais desejam e esperam de seus funcionários é o comprometimento afectivo, pois, essa qualidade tão ansiada remete ao facto deste assumir um compromisso com responsabilidade, dar garantias do seu empenho com as tarefas executadas (Spector, 2010).

Para Newstrom (2008, p. 122) o não comprometimento dos empregados é frequentemente a causa da queda estrutural de uma organização, como a grande rotatividade de mão-de-obra ea diminuição do ritmo de trabalho. Já atitudes favoráveis à organização como o comprometimento dos colaboradores trazem resultados positivos.

O comprometimento organizacional está relacionado com as atitudes do indivíduo, que por sua vez é consequência do nível de satisfação nas actividades que executa.

\section{Correlação entre a satisfação no trabalho e o comprometimento organizacional}

Segundo Mowday, SteersePoter (1979, citados por Rojot, Roussel e Vandenberghe, 2009) o comprometimento organizacional é um constructo mais 
amplo que a satisfação no trabalho. O primeiro constructo reflecte uma resposta geral do indivíduo à organização como um todo. O segundo, por sua vez, reflecte uma resposta do indivíduo às suas tarefas ou a certos aspectos de seu trabalho.

Os autores, também acrescentam que o comprometimento tende a ser mais estável ao longo do tempo, do que a satisfação. Para eles, embora alguns eventos do dia-a-dia no ambiente de trabalho possam afectar o grau de satisfação de um indivíduo, tais eventos transitórios não levam este indivíduo a reavaliar seu comprometimento para com a organização como um todo.

Embora o comprometimento organizacional e a satisfação no trabalho sejam constructos diferentes, alguns autores demonstram a existência de uma correlação entre eles. Alguns estudos avaliaram a correlação entre a satisfação no trabalho e o comprometimento organizacional e obtiveram resultados significativos.

MathieueZajac (1990, citados por Rojot, Roussel e Vandenberghe, 2009) por exemplo: realizaram uma meta análise que avaliou a correlação entre o comprometimento organizacional afectivo, normativo e a satisfação no trabalho. Os autores observaram que a satisfação no trabalho apresenta uma correlação maior com o comprometimento afectivo $(r=0,68)$ do que com o comprometimento normativo $(r=0,23)$.

\section{METODOLOGIA}

O objectivo deste capítulo é demonstrar em detalhes, a forma metodológica adoptada para realização deste trabalho científico. Trata-se de uma pesquisa de campo, tem como principal característica de o objecto/fonte ser abordado no seu ambiente próprio. A colheta dos dados é feita nas condições naturais em que os fenómenos ocorrem, sendo assim, directamente observados sem intervenção e manuseio por parte do pesquisador (Severino, 2007).

\section{Unidade em Análise}

O Hospital Geral de Luanda é uma estrutura da rede especializada que conta com os serviços e unidades necessárias para uma assistência a nível da 
Análise da correlação entre a satisfação no trabalho e o comprometimento organizacional: estudocom os enfermeiros da pediatria do hospital geral de luanda região sanitária, presta serviços de diagnóstico, tratamento e internamento, com pessoal sanitário, (médicos e enfermeiros) num espaço físico de uso exclusivamente sanitário.

O Hospital Geral de Luanda (HGL) foi inaugurado no dia 3 de Fevereiro de 2006 em cerimónia presidida pelo ex-presidenteca República de Angola, José Eduardo dos Santos. O mesmo está localizado nas proximidades do cemitério da Camama, no município de Talatona, tem a capacidade para internar mais de 500 pacientes.

\section{População e amostra}

A população deste estudo compreende todos os enfermeiros (58) da Pediatria do Hospital Geral de Luanda. A amostra estudo é composta de 40 enfermeiros, que corresponde a $69 \%$ dos funcionários, com idades compreendidas entre os 24 à 48 anos.

\section{Tipo de pesquisa}

O tipo de pesquisa deste estudo caracteriza-se pela forma quantitativa. " É objectiva, busca leis explicativas, mede aquilo que considera ser realidade estatística e imóvel com o intuito de produzir ou descobrir leis universais". Busca uma análise de quantidades das informações para que os resultados se constituam em medidas precisas e confiáveis de objecto em estudo (Severino, 2007, p. 118).

\section{Método}

O metotod usado neste estudo foi o exploratório-descritivo, com o objectivo de "proporcionar maior familiaridade com o problema, com vista a torná-lo mais explícito" (Gil, 2009, p. 41).

\section{Instrumentos utilizados}

Para a recolha dos dados deste estudo utilizou-se questionários. O referido instrumento era composto por questões auto-explicativas e foi distribuído por 
acessibilidade, entre os indivíduos do grupo funcional, à medida que se propuseram em responder.

Os questionários são compostos por três partes, que são: a primeira parte aborda questões sobre os dados sócio demográficos, a segunda parte, questões sobrea satisfação no trabalho e a terceira, questões sobre o comprometimento organizacional.

As questões sobre os dados sócio demográficos foram especialmente desenvolvidas para o contexto deste trabalho. Para a determinação da satisfação no trabalho recorremos à versão reduzida (27 itens) da Escala de Satisfação no Trabalho, desenvolvida por Siqueira (2008). Já para a determinação do comprometimento organizacional, recorremos ao instrumento de 17 itens desenvolvidos por Meyer, Allene Smith (1993, citados por Rojot, Roussel e Vandenberghe, 2009).

Nos questionários empregados neste estudo, as questões sobre a satisfação no trabalho e o comprometimento organizacional foram adaptadas de seus questionários originais para maior adequação ao tipo de organização pesquisada (hospital).

As respostas às questões sobre a satisfação no trabalho foram avaliadas por meio de uma escala de Likert, que varia de 1 (um) a 5 (cinco), sendo 1 - para muito insatisfeito, 2 - insatisfeito, 3 - indeciso, 4 - satisfeito e 5 - para muito satisfeito. Já as respostas às questões sobre o comprometimento organizacional foram avaliadas por meio das respostas sendo, D.T ou D.P (discordo total ou discordo parcial), N (não concordo nem discordo) e C.Tou C.P (concordo total ou concordo parcial).

\section{Procedimentos}

Os dados foram recolhidos no mês de Julho de 2014 por meio de questionários que foram entregues aos funcionários que aceitaram em participar da pesquisa. A autorização para a recolha de dados foi oficializada por meio da assinatura de duas cartas em vias iguais. 
Análise da correlação entre a satisfação no trabalho e o comprometimento organizacional: estudocom os enfermeiros da pediatria do hospital geral de luanda

O período da recolha de dados foi de 15 dias. Foram entregues 58 questionários e foram devolvidos 40 questionários, determinando uma taxa de $69 \%$ questionários preenchidos.

O tratamento estatístico dos dados dos questionários de satisfação no trabalho e comprometimento organizacional foi realizado no sistema integrado Excel, através de médias e correlação. Os resultados foram apresentados individualmente, depois agrupados, dependendo do tipo de necessidade (fisiológica, segurança, social, estima e auto - realização), factores (higiénicos e motivacionais) e dependendo do tipo de comprometimento (afectivo, contínuo e normativo). A seguir apresentar-se-à as tabelas que ajudaram para a interpretação dos resultado, tendo em conta as médias de resposta (tabela $n^{\circ} 1$ e tabela $n^{\circ} 2$ ).

\section{Tabela no1 - Avaliação do grau de satisfação no trabalho e comprometimento organizacional}

\begin{tabular}{|c|c|}
\hline Interpretação dos resultados & Média \\
\hline Grau de satisfação e comprometimento baixo & $1,00-2,99$ \\
\hline Grau de satisfação e comprometimento médio & $3,00-3,99$ \\
\hline Grau de satisfação e comprometimento alto & $4,00-5,00$ \\
\hline
\end{tabular}

Fonte: Siqueira (2008) e Carvalho (2009).

Tabela no2 - Avaliação do grau de correlação

\begin{tabular}{|c|c|}
\hline Interpretação & Média \\
\hline Muito forte & $0,9-1$ \\
\hline Forte & $0,7-0,8$ \\
\hline Moderado & $0,4-0,6$ \\
\hline Fraca & $0,2-0,3$ \\
\hline Muito fraca & 0,1 \\
\hline
\end{tabular}

Fonte: Carvalho(2009). 


\section{Apresentação, análise e discussão dos resultados}

De uma forma geral, quanto as características sócio demográficas da amostra constata-se que $82,5 \%$ são do género feminino e $17,5 \%$ são do género masculino. Destes 50\% (20), têm idades compreendidas entre os 35 - 44 anos, $30 \%$ (12) têm idades compreendidas entre os 24 - 34 anos e $20 \%$ (8) têm 45 anos ou mais.

\section{Análise da satisfação no trabalho}

A seguir apresentaremos um gráfico, que ilustrará os nossos resultados, segundo a teoria das necessidades de Maslow:

Gráfico nำ - Satisfação no trabalho dos enfermeiros da Pediatria do HGL referente as cinco necessidades segundo a hierarquia de Maslow - 2014

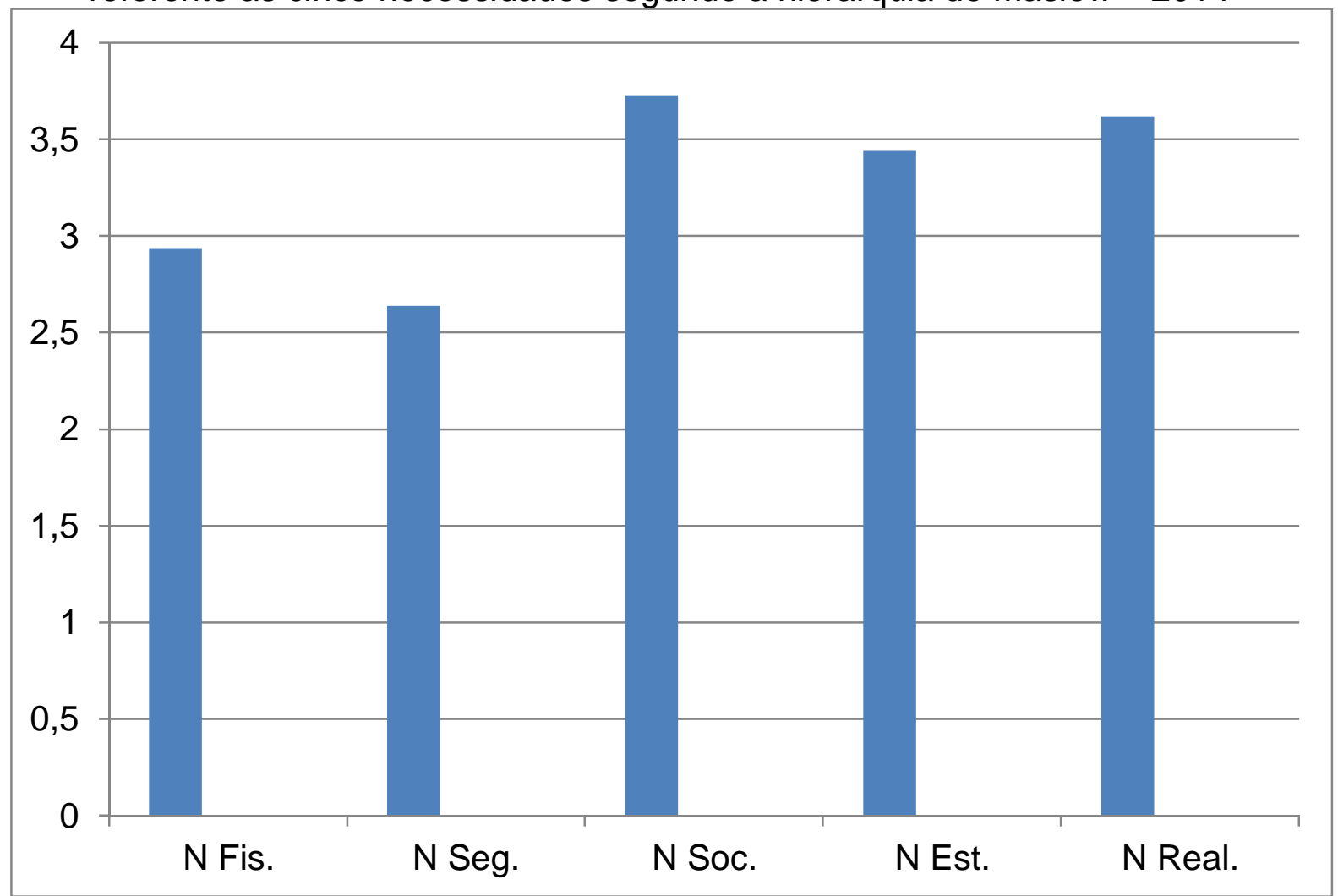

Fonte: Elaboração própria 
Análise da correlação entre a satisfação no trabalho e o comprometimento organizacional: estudocom os enfermeiros da pediatria do hospital geral de luanda

No que concerne as necessidades fisiológicas encontra-se uma média geral de 2,94 o que indica um grau de satisfação baixo. Os enfermeiros estão com grau de satisfação baixo no item referente as condições físicas de trabalho $(2,43)$ e apresentam um grau de satisfação médio nos itens que se referem ao número de dias de férias $(3,80)$ e a carga horária $(3,43)$.

No que diz respeito as condições de trabalho constatou-se que o hospital temcarência de material gastável (luvas, seringas, glândulas, borboletas, medicamentos para os primeiros socorros e até mesmo algodão) a escassez destes materiais gastáveis repercute na tomada de decisão dos profissionais de enfermagem, e isto implica muitas vezes na interrupção da assistência prestada ao paciente. Diante desta situação os pacientes estão sujeitos a possíveis riscos que a falta de materiais pode ocasionar, tais como: infecções, estresse e aumento do tempo de hospitalização.

Chiavenato (1992, p.153) diz que as condições de trabalho são as circunstâncias físicas que envolvem os empregados, enquanto ocupante de um cargo na organização. As pessoas no trabalho são profundamente influenciados por três grandes grupos a destacar:

- Condições ambientais de trabalho: refere-se á iluminação, ruídos, temperatura.

- Condições de tempo: a duração da jornada de trabalho, às horas extras e o período de descanso.

- Condições sociais: organização informal.

No que tange ao número de dia de férias, alguns enfermeiros afirmaram não gozar de um mês de férias seguidos, ou seja, muitos deles (chefes de turnos e enfermeiros especializados) gozam apenas quinze (15) dias de férias um mês e outros quinzes depois de dois ou três messes.

Logo, estas informações corroboram com as de Rodrigues (2006) o qual afirma que, a cada 12 meses é direito do trabalhador o período de descanso remunerado, este pode ter duração fracionada, por exemplo: 15 dias em um mês e mais 15 depois, ou 10 dias em uma época do ano e mais 20 em outra. Ou a pessoa pode tirar 20 dias para descansar e vender 10, ou seja, ela trabalha esse 
período e recebe um valor por se privar da folga garantida pela constituição, além da remuneração salarial.

No que concerne a carga horária, alguns enfermeiros apresentam grau de satisfação médio por afirmarem que muitas vezes são rendidos tarde ou até mesmo não chegam a ser rendidos pelos colegas, principalmente por aqueles que estão a frequentar o ensino superior.

Para Maslow (1970, citado por Myers, 2006) há insatisfação das necessidades fisiológicas quandoo confronto no local de trabalho e a remuneração é inadequada. O grande impacto sobre condições de trabalho ocorre no final do século XVIII quando alguns sectores produtivos como vidraria, metais e outros, começam a exigir uma crescente concentração de mão-de-obra, com a inerente diminuição do peso do trabalho artesanal na estrutura económica da sociedade. (Freitas, 2011, p. 24).

A nova forma de organização de trabalho baseada na entrada do capital no processo produtivo, na propriedade das ferramentas e matérias-primas, no controlo e venda da produção pelo proprietário do capital, no estabelecimento de horários de trabalho, na divisão do trabalho e nas escalas horárias, acarreta uma nova concepção de trabalho fundada na produtividade, no liberalismo económico, em novas técnicas e na submissão do trabalho à lei da oferta e da procura. (Id, 2011).

A recompensa concedida aos funcionários pelo trabalho realizado na organização é a remuneração: salário, benefícios, bolsa de estudos, gratificações, bônus, décimo terceiro salário, participação nos resultados e outros.

Chiavenato (2008) afirma: "Ela é importante do ponto de vista de cada pessoa, como uma necessidade vital. Pagamento é o meio pelo qual uma pessoa proporciona satisfação de suas necessidades e das de sua família".

Por isso, se a remuneração não for muito bem administrada pela direção da organização poderá causar a saída dos seus empregados. E para definir uma recompensa adequada, a empresa precisa levar em consideração 4 pontos importantíssimos: 
Análise da correlação entre a satisfação no trabalho e o comprometimento organizacional: estudocom os enfermeiros da pediatria do hospital geral de luanda

- A qualidade da remuneração concedida de acordo a situação do mercado de trabalho: se a oferta de emprego é grande e a procura é pequena, há necessidade de garantir uma recompensa melhor, todavia se a procura por emprego é alta e a oferta é baixa, então as organizações poderão definir uma remuneração menos dispendiosa;

- A competitividade da remuneração: caso o colaborador note que há empresas oferecendo uma recompensa equiparada num trabalho mais satisfatório ou pagando mais por emprego equivalente é provável que deixem a organização;

- A equidade ou justiça na remuneração dos cargos internos: o funcionário que percebe que há injustiça no valor de sua remuneração (Ex.: colaborador recebe um salário pequeno e realiza uma tarefa complexa, enquanto outro que desempenha tarefa mais simples recebe uma remuneração melhor) estará propenso a trocar de empregadora;

- O merecimento do funcionário que recebe melhorias na remuneração: há empresas que optam por aumentar igualmente a remuneração de todos os colaboradores, o que pode causar a perda de bons funcionários por não notarem diferenciação do seu salário para aqueles que não apresentam o mesmo desempenho.

A remuneração é um fator crucial para que as organizações mantenham seus funcionários motivados e evitem a rotatividade de pessoal, por isso os Executivos de $\mathrm{RH}$ necessitam fazer análises constantes da recompensa oferecida e dos seus impactos na empresa.

No que diz respeito as necessidades de segurança, encontra-se uma média geral de 2,64 que representa um grau de satisfação baixo. Os enfermeiros apresentam grau de satisfação baixo nos itens que têm a ver com a remuneração mensal $(2,40)$, pagamento de trabalho extraordinário $(2,10)$, aumentos salariais $(2,40)$, estabilidade e segurança de trabalho $(2,60)$, oportunidade de formação $(2,85)$, oportunidade de participação que o superior dá $(2,65)$ e a preocupação do superior com o bem-estar $(2,35)$. E grau médio de satisfação nos itens que 
referem-se a oportunidade de desenvolvimento de competências $(3,03)$ e as perspectivas futuras em relação ao trabalho $(3,35)$.

Para Maslow, há insatisfação das necessidades de segurança quando o tipo de trabalho e o seu ambiente são mal estruturados, as políticas da empresa são instáveis e imprevisíveis.

Segundo Neswtrom (2008) e Spector (2010), o salário é um importante factor econômico para os trabalhadores, não obstante, representa certo nível de status diante da sociedade, representa para os empregados aquilo que os patrões pensam deles, e é uma forte ferramenta para se motivar o colaborador. Além desses motivos explícitos, a remuneração salarial está ligada as necessidades do indivíduo, desde as basicas (alimentação e segurança) até mais supérfluas.

No que concerne as necessidades sociais, encontra-se uma média geral de 3,73 o que indica um grau de satisfação médio. Segundo Maslow, a insatisfação dessas necessidades conduz á falta de adaptação social e a solidão, cria debilidade no reconhecimento interpessoal o que afecta a produtividade.

Spector (2012) afirma que as relações com os colegas de trabalho podem constituir o factor mais importante na decisão de permanecer ou não em um emprego e podem afectar a extensão na qual os colegas trabalham bem juntos.

No que diz respeito as necessidades de estima, encontra-se uma média geral de 3,54 que representa um nível de satisfação médio. Maslow (1970, citado por Myers, 2006) afirma que, a não realização das necessidades de estima pode causar sentimentos de inferioridade, fraqueza, dependência e desamparo, os quais podem levar ao desânimo.

No que se refere as necessidades de auto - realização, encontra-se uma média geral de 3,62 (grau de satisfação médio). Este último ponto da pirâmide de Maslow é o exemplo típico de necessidade procurada por um grande número de funcionários, muito cedo na sua vida profissional às vezes mesmo antes de integrar a empresa (Rojotet, Rossuel e Vandenberghe, 2009, p. 215).

Segundo Robbins (1999, citado por Chiavenato, 2010) toda organização com um programa de progressão de carreira e oportunidades bem gerido e aplicado, tem tudo para dar certo uma vez que, os trabalhadores a partida sabem 
Análise da correlação entre a satisfação no trabalho e o comprometimento organizacional: estudocom os enfermeiros da pediatria do hospital geral de luanda ou fazem o seu plano de ascensão em função das suas habilidades, tempo de trabalho, comportamento e comprometimento com a própria organização, isto é, cada um em função do seu desempenho sabe a que patamar na organização pode atingir e em quanto tempo.

A seguir apresentaremos um gráfico, que ilustrará os nossos resultados segundo a teoria dos dois factoresde Herzberg:

Gráfico no 2 - Satisfação no trabalho dos enfermeiros da Pediatria do HGL referente a teoria dos dois factores de Herzberg- 2014

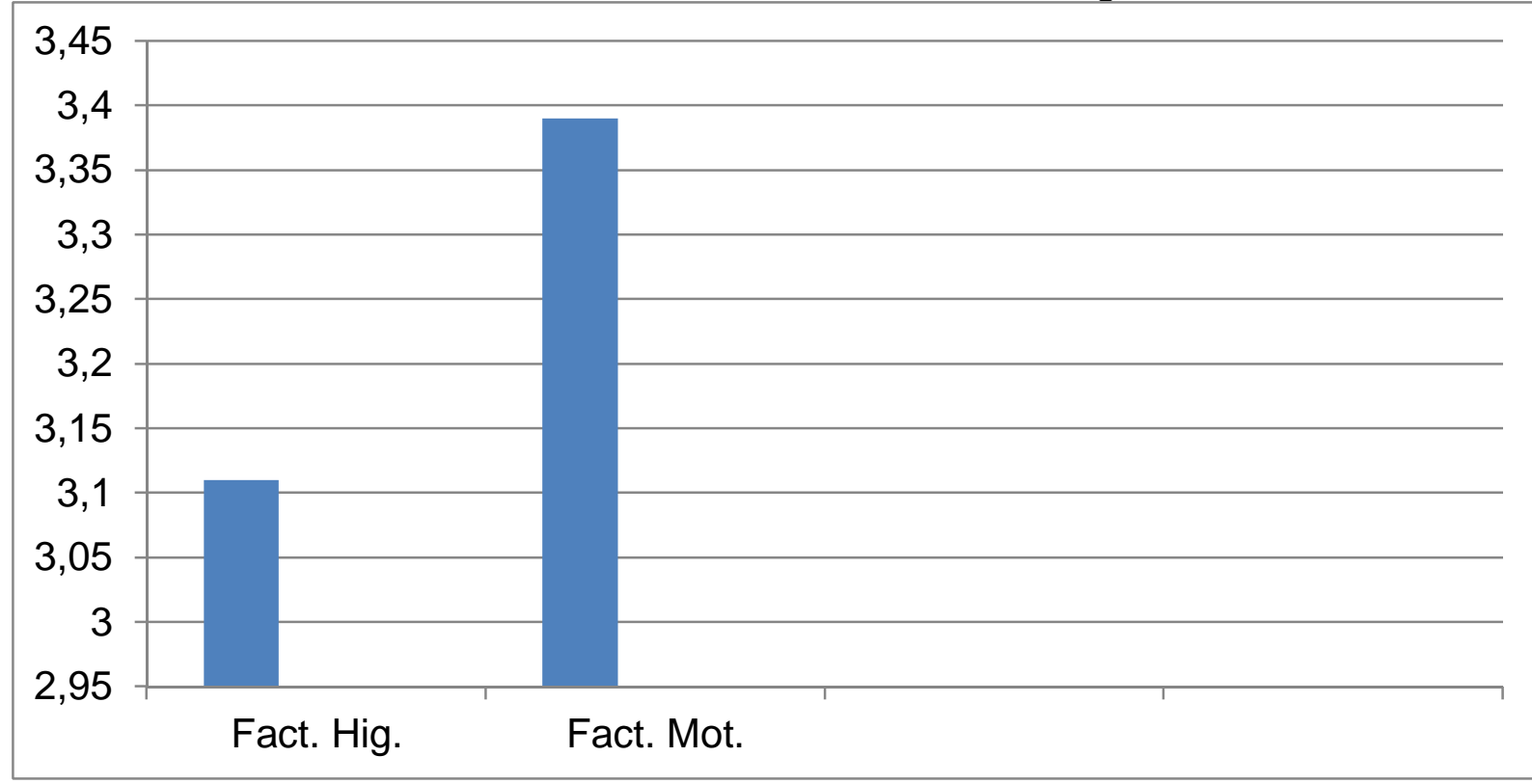

Fonte: Elaboração própria.

Os resultados foram divididos seguindo os lineares de Herzberg (1959, citado por Teixeira, 2005) tal como se pode observar no gráfico acima, os factoreshigiénicos apresentam uma média de 3,11 que indica um grau de satisfação médio.

Segundo Chiavenato (2010, p. 279) ninguém trabalha de graça. Como parceiro da organização cada funcionário esta interessado em investir com o trabalho, dedicação e esforço pessoal, com os seus conhecimentos e habilidades desde que receba uma retribuição adequada. As organizações estão interessadas 
em investir em recompensas para as pessoas desde que delas possam receber contribuições ao alcance dos seus objectivos.

Os trabalhadores devem ser considerados como parte da organização, sentindo deste modo a sua dignidade respeitada, bem como, satisfeitas as suas necessidades pessoais e familiares. Desta forma deparamo-nos com um maior nível de produção nas empresas.

Os factores motivacionais apresentam uma média geral de 3,39 que indica um grau de satisfação médio.

Segundo Luz (1995, citado por Chiavenato, 2010) por isso, as empresas actualmente dão importância à qualidade das relações entre supervisores e subordinados, buscando o bem-estar da organização como um todo. O relacionamento entre trabalhadores e chefia é importante porque cria um clima de confiança, respeito e consideração buscando maior eficácia organizacional.

Contudo, podemos dizer que, os enfermeiros do HGL estão mais satisfeitos com os factoresmotivacionaisem relação aos factores higiénicos. Segundo o referido autor, os factores higiénicos são factores extrínsecos, que se localizam no ambiente que rodeia os indivíduos: salário; benefícios sociais; tipo de chefia; condições físicas e ambientais de trabalho; políticas da empresa; clima que reina entre as pessoas no seio da empresa e a relação com os colegas.

Já os factores motivacionais são factores intrínsecos, porque estão sob o controlo do indivíduo. Estes envolvem: sentimentos de crescimento pessoal e reconhecimento profissional.

As conclusões de Hezrberg (1959, citado por Teixeira, 2005) foram diferentes das de Maslow. Hezrberg considera que os factores higiénicos são capazes de reduzir ou anular a insatisfação, mas não conseguem conduzir à motivação das pessoas. Apenas contribui para a prevenção de problemas e por isto se chamam factores higiénicos. O autor concluiu que, pelo contrário, os factores motivacionais podem contribuir para elevados níveis de satisfação e assim resultar em motivação das pessoas, situação que em nosso estudo foi interessante encontrar. 
Análise da correlação entre a satisfação no trabalho e o comprometimento organizacional: estudocom os enfermeiros da pediatria do hospital geral de luanda

\section{Análise do comprometimento organizacional}

A seguir apresentaremos um gráfico onde estará representado os tres tipos de comprometimento organizacional e suas respectivas médias, referente aos dois generos (Feminino e Masculino).

Gráfico nํ - Comprometimento organizacional dos enfermeiros da Pediatria do HGL referente ao género- 2014

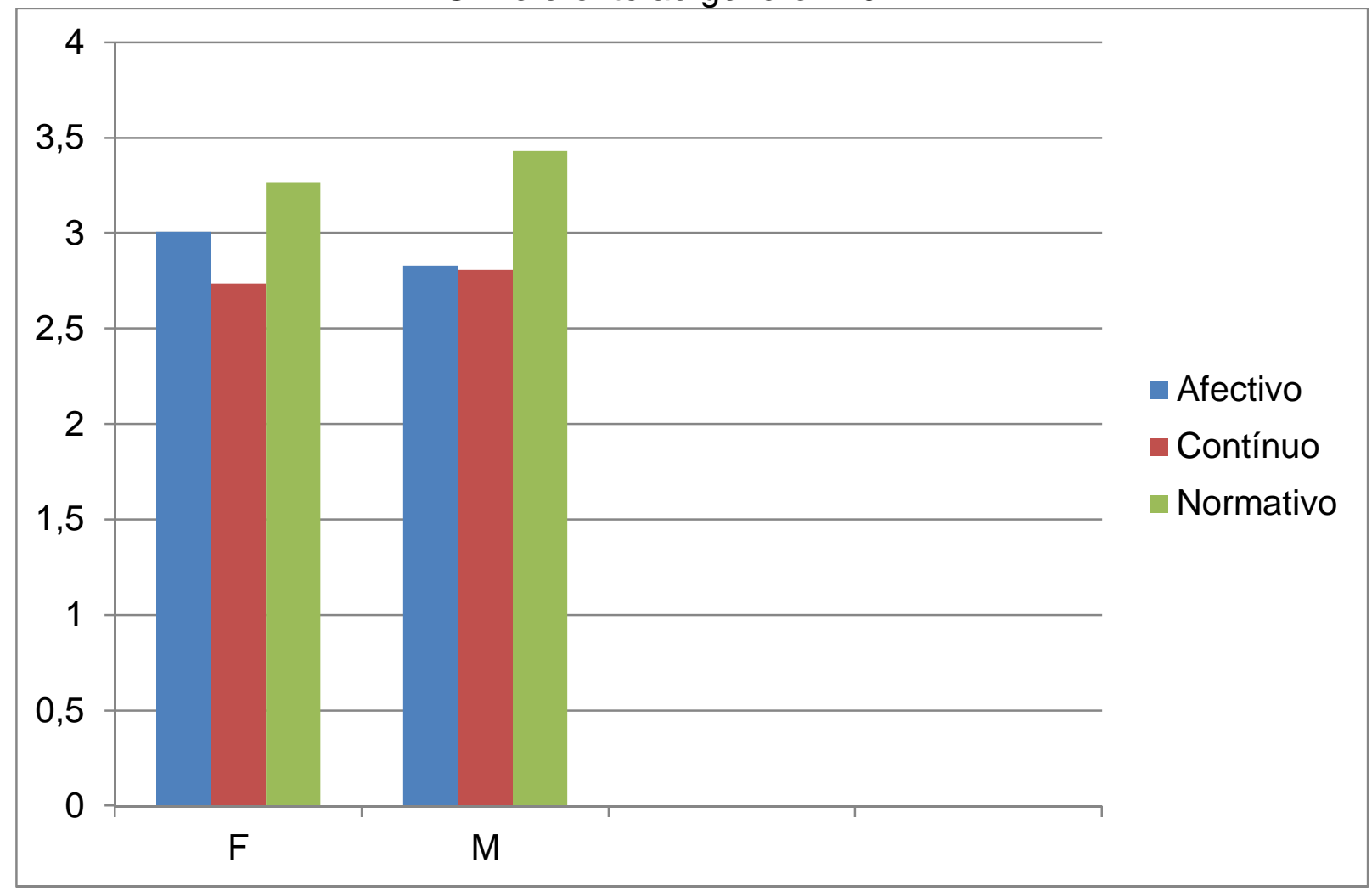

Fonte: Elaboração própria

No que concerne ao comprometimento afectivo pode-se observar que o género feminino apresenta uma média geral de 3,01 que indica um grau de comprometimento médio. O género masculino apresentauma média geral de 2,83 (grau de comprometimento baixo). Já o género feminino apresenta uma média geral de 2,74 e o género masculino apresenta uma médiageral de 2,81 (ambas indicam um grau de comprometimento baixo). 
No que concerne o comprometimento normativo o género feminino apresenta uma média geral de 3,27 e o género masculino 3,43 (ambas com um grau de comprometimento médio).

Assim, na análise por género, aprecia-se que o género masculino está mais comprometido, excepto no comprometimento afectivo. Contudo, os nossos resultados vão ao encontro com os resultados de Mowaday (1982; Biau, 1964 e Gouldner, 1960 citados por Rojot,Roussel e Vandenberghe, 2009) que dizem o género masculino tem maior índice de comprometimento.

A seguir apresentaremos um gráfico onde estará representado os tres tipos de comprometimento organizacional e suas respectivas médias, referente a faixa etária.

Gráfico no 4 - Comprometimento organizacional dos enfermeiros da Pediatria do HGL referente ao faixa etária -2014

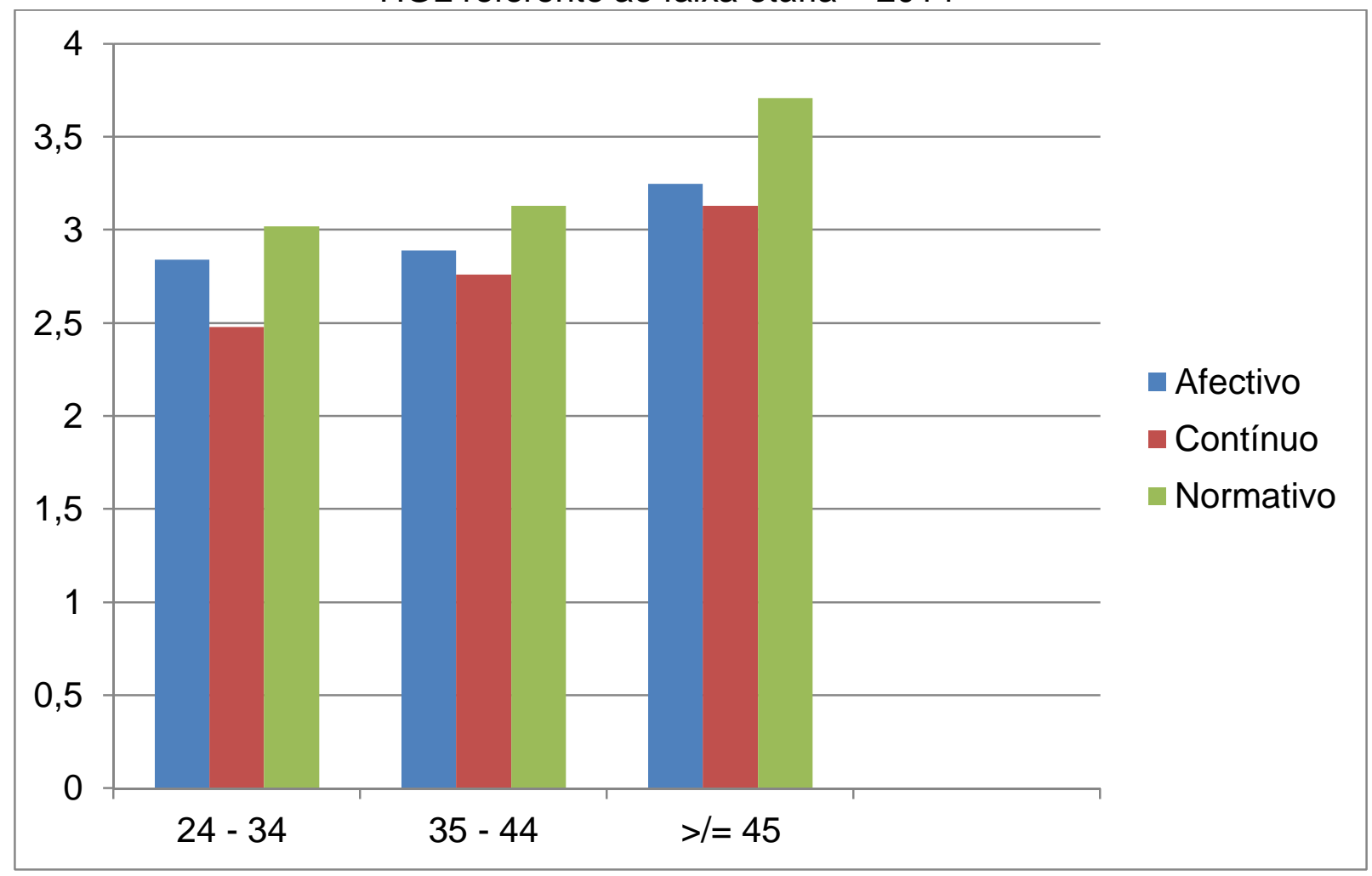

Fonte: Elaboração própria 
Análise da correlação entre a satisfação no trabalho e o comprometimento organizacional: estudocom os enfermeiros da pediatria do hospital geral de luanda

No que diz respeito ao comprometimento afectivoobservou-se que os enfermeiros com idades compreendidas entre os 24 - 34 anos, apresentam uma média geral de 2,84.Já os enfermeiros com idades compreendidas entre os 35 44 anos, apresentamuma média geral de 2,89 (ambas indicam um grau de comprometimento baixo). Os enfermeiros com idade igual ou superior aos 45 anos apresentam uma média geral de 3,25 que representa um grau de comprometimento médio.

No que concerne o comprometimento contínuo, constatou-se que os enfermeiros com idades compreendidas entre os $24-34$ anos, apresentam uma média geral de 2,48. Já os enfermeiros com idades compreendidas entre os $35-$ 44 anos, apresentamuma média geral de 2,76 (ambas representam um grau de comprometimento baixo). Os enfermeiros com idade igual ou superior aos 45 anos apresentamumamédia geral de 3,13 que indica um grau de comprometimento médio.

No que diz respeito ao comprometimento normativo, observou-seque os enfermeiros com idades compreendidas entre os $24-34$ anos, apresentamuma média geral de 3,02. Já os enfermeiros comidades compreendidas entre os $35-$ 44 anos, apresentamuma média geral de 3,24 . Os com idade igual ou superior aos 45 anos apresentam uma média geral de 3,71. Todas representam um grau de comprometimento médio.

Assim pode-se dizer que os enfermeiros com idade igual ou superior aos 45 anos estão mais comprometidos com a organização. Os nossos resultados vão de encontro aos de Mathieu e Zajac (1990; Medeiros, 1997, citados por Rojot, Roussel e Vandenberghe, 2009) que dizem, os mais velhos são mais comprometidos. Eles têm um vínculo emocional com a organização e sentem-se identificados com os problemas da mesma. O mesmo cresce a medida que aumenta a idade.

A seguir apresentar-se-á um gráfico onde estará representado a correlação entre o a satisfação no trabalho e o comprometimento organizacional. 
Gráfico ํo 3 - Correlação entre a satisfação no trabalho e o comprometimento organizacional- 2014

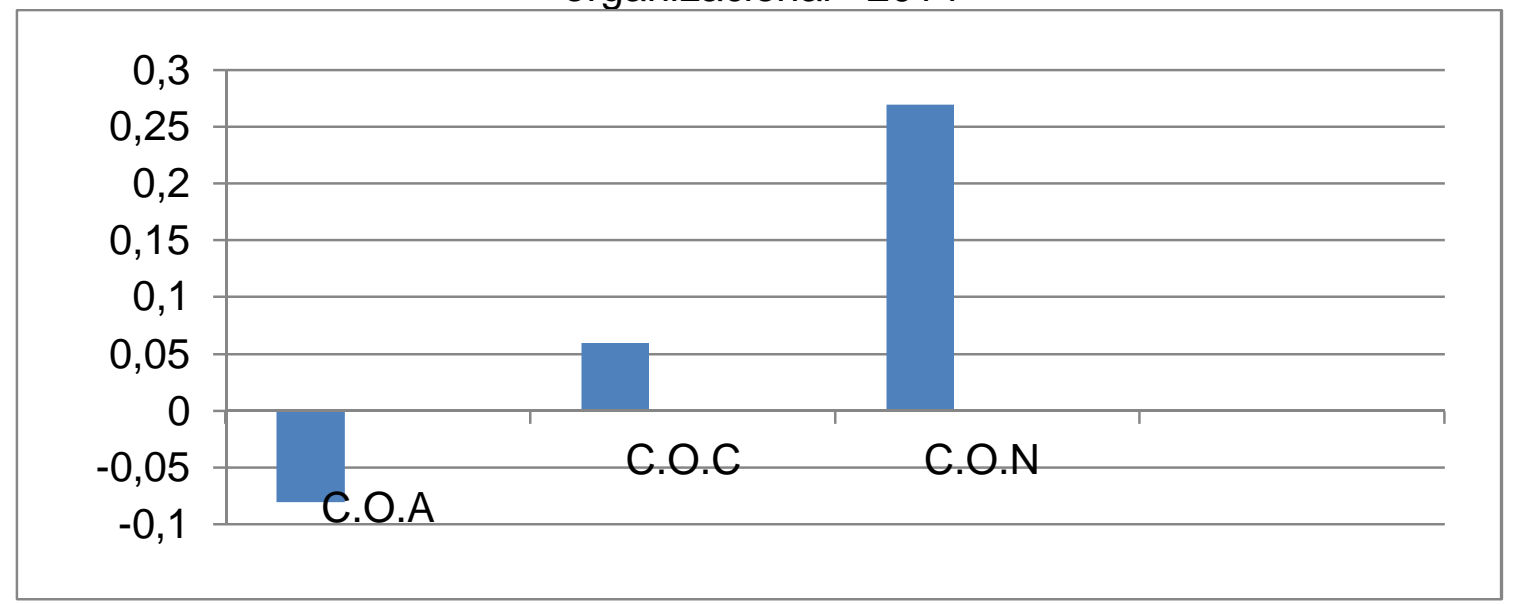

Fonte: Elaboração própria

No que concerne a correlação entre a satisfação no trabalho e o comprometimento organizacional afectivo dos enfermeiros da Pediatria do HGL, não foram observadas correlações significativas entre o comprometimento afectivoe a satisfação no trabalho $(r=-0,08)$ esta por sua vez indica uma correlação negativa nula. Os nossos resultados são contrários aosencontradospor Meyer, Allen e Smith (1993, citados por Rojot, Roussel e Vandenberghe, 2009) ao realizarem um estudo com enfermeiros, observaram o comprometimento afectivo e a satisfação no trabalho apresentam uma correlação moderada $(r=0,42)$.

Já Meyeret, Herscovitch e Topolnytsky (2002) também observaram correlações moderadas um pouco mais elevada entre o comprometimento afectivo e a satisfação no trabalho $(r=0,65)$.

No que concerne a correlação entre o comprometimento contínuo e a satisfação no trabalhopor sua vez, não foram observadas correlações significativas, temos $(0,06)$. De qualquer maneira, os nossos resultados vão de encontro aos de Meyer, Allen e Smith (1993, citados por Rojot, Roussel e Vandenberghe, 2009) os quais observaram que ambos os constructos não apresentam uma correlação significativa $(0,02)$. 
Análise da correlação entre a satisfação no trabalho e o comprometimento organizacional: estudocom os enfermeiros da pediatria do hospital geral de luanda

Já Meyer, HerscovitcheTopolnytsky (2002) encontraram uma correlação negativa praticamente nula $(r=-0,07)$ entre o comprometimento contínuo e a satisfação geral no trabalho.

Segundo Spector (2012) apesar de a relação entre o comprometimento contínuoe a satisfação no trabalho ser relativamente pequena, esses resultados sugerem que as pessoas que trabalham devido a um vínculo emocional tenderão a apresentar um desempenho melhor, mas aqueles que trabalham devido a um senso de obrigação na verdade apresentarão um desempenho pior.

No que diz respeito a correlação entre o comprometimento normativo e a satisfação no trabalho foram observadas uma correlação de $(r=0,27)$ que indica uma correlação baixa. Logo, os nossos resultados são diferentes aos encontrados por Meyer, Allen e Smith (1993, citados por Rojot, Roussel e Vandenberghe, 2009) que relataram ter encontrado uma correlação moderada entre o comprometimento normativo e a satisfação $(r=0,37)$ que era a correlação observada quando o comprometimento afectivo substituía o normativo.

Da mesma maneira, Meyer, HerscovitcheTopolnytsky (2002) observaram uma correlação menor entre o comprometimento normativo e a satisfação ( $r=$ $0,31)$ do que entre ocomprometimento afectivo e a satisfação $(r=0,49)$.

\section{CONSIDERAÇÕES FINAIS}

O presente trabalho teve a pretensão de analisar a correlação entre a satisfação no trabalho e o comprometimento organizacional dos enfermeiros da Pediatria do Hospital Geral de Luanda.

Dos 58 enfermeiros que constituem a população alvo, apenas 40 enfermeiros fizeram parte da amostra. Para a recolha de dados aplicou-se questionários, e as respostas foram analisadas estatisticamente, incluindo uma descrição de frequência, percentagens e médias cujos resultados foram apresentados por gráficos. Utilizou-se o tipo de estudo descritivo-exploratório. Os dados foram analisados quantitativamente.

Foi possível constatar, que os enfermeiros da Pediatria do Hospital Geral de Luanda, apresentam baixo grau de satisfação nos itens referentes a remuneração 
mensal, oportunidades de formação, pagamentos de trabalho extraordinário, aumentos salariais, condições físicas de trabalho e a preocupação de superior com o bem-estar. Grau de satisfação médio nos itens que têm a ver com os serviços prestados a população, natureza das tarefas que executa, relações com os doentes, relações com os familiares dos doentes, relações com os superiores, responsabilidades exigidas, número de dias de férias, importância do trabalho e o prestígio/status social que a profissão dá. E um grau de satisfação alto na relação com os colegas.

No que respeita ao comprometimento, constatou-se grau baixo de comprometimento afectivo e contínuo, e grau médio de comprometimento normativo. De maneira geral aprecia-se que o tipo de comprometimento predominante entre os enfermeiros da Pediatria do HGL é o comprometimento normativo.

No que concerne a verificação de cada um dos tipos de comprometimento atendendo os antecedentes género, observou-se que o género masculino está mais comprometido em relação ao feminino, excepto no comprometimento afectivo.

Atendendo a nossa questão fundamental pode-se responder que a correlação entre a satisfação no trabalho e comprometimento dos enfermeiros da Pediatria do HGL é de - 0,08 para o comprometimento afectivo; 0,06 referente ao comprometimento contínuo e 0,27 para o comprometimento normativo.

Tratando-se de um tema importante na vida de qualquer ser humano, espera-se que mais pesquisadores sintam-se motivados a dar continuidade ao estudo da satisfação no trabalho e comprometimento organizacional, pois, todo comportamento humano é voltado para a satisfação das necessidades humanas.

Por tanto, para que qualquer organização conserve a sua força de trabalho deverá ter presente não apenas as suas próprias metas e objectivos, mas também, as necessidades e expectativas dessa mesma força, para que não haja diminuição no seu rendimento ou até abandono da organização.Sendo assim, conseguimos dar resposta aquestão fundamental e aos objectivos propostos no trabalho. 
Análise da correlação entre a satisfação no trabalho e o comprometimento organizacional: estudocom os enfermeiros da pediatria do hospital geral de luanda

\section{REFERÊNCIAS BIBLIOGRÁFICAS}

Bowdicch, James e Bouno, Antony. (2000).Elementos do comportamento Organizacional. $1^{\underline{a}}$ ed., ver.Pioneira. Brasil.

Carvalho, Eduardo. (2009). Metodologia do Trabalho Científico: Saber Fazer da investigação para dissertações e teses. $2^{\mathrm{a}}$ ed.Escolar Editora.Portugal.

Cecagno, Diana (2005). Satisfação de uma Equipe de Enfermeiros quanto à Profissão e Emprego. Disponível em: http://www.scielo.br/pdf/rsp/v39n4/25542.pdf consulta: 09-05-14.

Chiavenato, Idalberto. (1992). Gestão das Pessoas: O Novo Papel dos Recursos Humanos nas Organizações.Campus. Brasil.

Chiavenato, Idalberto. (2008). Recursos humanos: o capital humano das organizações. $8^{a}$ ed. 4. Reimpr. Atlas.Brasil.

Chiavenato, Idalberto. (2010). Comportamento Organizacional: A Dinâmica do Sucesso nas Organizações. $2^{\underline{a}}$ ed.Elsevier. Brasil.

Ferreira, Carvalho, Neves José e Caetano António. (2011). Manual de Psicossociologia das Organizações. Instituto Piaget. Portugal.

Freitas, Luís Conceição. (2011). Manual de Segurança e Saúde do Trabalho. $2^{\mathrm{a}}$ ed.Silabo. Portugal.

Gil, António. (2009). Como Elaborar Projectos de Pesquisa. 4aㅡ ed.Brasil: Cortez.

Meyer, J. P e Herscovitch, L. (2001).Comprometimento dentro da Organização. $3^{\underline{a}}$ ed., rev. Vol.11. Instituto Piaget. Portugal.

Meyer,J. P; Herscovitch, L. e Topolnytsky L. (2002). Comportamento Organizacional Afectivo, Contínuo e Normativo. Disponível em: http://www.bd.camara.gov.br/bd/bitstream/handl consulrta: 25-04-14.

Muchinsky, Paul. (2004). Psicologia Organizacional. $7^{\underline{a}}$ ed. Artmed. Brasil.

Myers, David. (2006). Psicologia. $7^{a}$ ed. LTC. Brasil.

Newstrom, Johm. (2008). Comportamento Organizacional: O Comportamento Humano no Trabalho.12 ed., rev.McGrow-Hill. Brasil.

Rodrigues, Del Cura (2006). Satisfação Profissional do Enfermeiro. Disponível em: http://www.scielo.br/pdf/rlae/v7n4/13485.pdf1999 consulta: 09-0514.

Rojot, Jacques, Roussel Patrice e Vanderberghe Christian (2009).Comportamento Organizacional. $3^{\circ}$ vol. Instituto Piaget. Portugal.

Sant'Anna, Anderson de Sousa; Moraes, Lúcio Flávio Renaout de e Kilimnik, Zélia Miranda (2005). Qualidade de Vida no Trabalho. $3^{\mathrm{a}}$ ed. Elsiever. Brasil.

Severino, António Joaquim. (2007). Metodologia do Trabalho Científico. $23^{\mathrm{a}}$ ed. ver. Cortez. Brasil.

Siqueira, Maria Marlene Matias. (2008). Medidas do Comprometimento Organizacional: Ferramentas de Diagnóstico e de Gestão. Artmed. Brasil.

Siqueira, Maria Marlene Matias e Gomide, Júnior. (2004). Vínculos do Indivíduo com o Trabalho e com a Organização. $3^{\circ}$ vol. Artmed. Brasil. 
Spector, Paul. (2002). Psicologia nas Organizações. Saraiva. Brasil.

Spector, Paul. (2006). Psicologia nas Organizações. $2^{\mathrm{a}}$ ed. Saraiva. Brasil.

Spector, Paul. (2010). Psicologia nas Organizações. $3^{a}$ ed. Saraiva. Brasil.

Spector, Paul. (2012). Psicologia nas Organizações. 4⿳a ed. Saraiva. Brasil.

Teixeira, Sebastião. (2005). Gestão das Organizações. 2 $2^{\underline{a}}$ ed. McGraw-Hill. Brasil. 